\title{
Nipple attachment in neonatal rats exposed to alcohol prenatally
}

\author{
EDWARD P. RILEY, SHARA L. BUNIS, and NORMAN GREENFELD \\ State University of New York, Albany, New York
}

\begin{abstract}
Previous work (Chen, Driscoll, \& Riley, 1982) has shown that rat pups exposed to alcoho! prenatally take longer to attach to the nipple of a test dam than do controls. However, the earliest age at which pups were tested was 3 days, which leaves open the possibility that the increased latencies might be the result of some altered postnatal experience. In the present study, rat pups whose mothers consumed liquid diets containing $35 \%$ or $0 \%$ ethanol-derived calories or lab chow were tested for nipple attachment before they had had an opportunity to suckle on their biological mothers. In support of previous data, animals exposed to alcohol prenatally were more apt to show longer attachment latencies than were controls.
\end{abstract}

Human infants born to alcoholic women have been described clinically as having a weak sucking response, which has been related to some central nervous system damage resulting from prenatal alcohol insult (Ulleland, 1972; Jones \& Smith, 1973; Ouellette, Rosett, Rosman, and Weiner, 1977). Martin, Martin, Streissguth, and Lund (1979, pp. 359-366) noted that infants of "social drinkers" took longer to initiate sucking on a nonnutritive nipple, took longer to reach a set sucking criterion, and had lower sucking pressure than offspring of women who had abstained from drinking during pregnancy. Thus, it appears that maternal alcohol consumption, even in moderate amounts, disrupts normal sucking behavior in human infants.

Rat pups exposed to alcohol prenatally also evidence a disruption in feeding behavior early in life (Chen, Driscoll, \& Riley, 1982). Offspring of mothers who consumed liquid diets containing 35\% ethanol-derived calories took longer to attach to the nipple of an anesthetized test dam than did offspring of either liquiddiet dams or lab chow control dams. This effect was noted to be age dependent, appearing only when testing was conducted on pups less than 12 days of age. In addition, the effect on attachment was independent of the type of test dam (exposed or not exposed to alcohol during pregnancy) and was not influenced by surrogate fostering. However, the youngest animals tested were 3 days postpartum. Recently, at a meeting at which these data were presented (Chen, Riley, \& Driscoll, 1981), the possibility was raised that the increase in attachment latency might not be the direct result of prenatal alcohol exposure but, rather, that early suckling experiences might have played a role, since even when

This work was partially supported by NIAAA Grant AA03249 to E. P. R. The authors would like to thank Gary Rockwood and Robert Hamlin for their help. The authors' mailing address is: Department of Psychology, State University of New York, Albany, New York 12222. offspring were fostered to nontreated dams, the pups did have their first exposure to suckling with their biological mothers. The present experiment was conducted to eliminate maternal influences following parturition that may have affected the previous results.

\section{METHOD}

The procedures used were identical to those described previously (Chen et al., 1982) and in use in our lab for some time (see also Ulug \& Riley, 1983; Plonsky \& Riley, 1983). Briefly, female Long-Evans hooded rats were provided with liquid diets, containing 35\% ethanol-derived calories (35\% EDC), as their sole source of fluid and food on Days 6 through 20 of pregnancy. A pair-fed control group that received an isocaloric, nonalcoholic diet was employed ( $0 \%$ EDC), as was an ad-lib lab chow control (LC). Each animal in the pair-fed 0\% EDC group was matched to a 35\% EDC mother and fed the amount consumed by that mother on a milliliter per kilogram body weight basis for any specific day of pregnancy. The animals were maintained in standard breeding cages beginning on Day 1 of pregnancy in a temperature- and humidity-controlled nursery with $12 \mathrm{~h}$ of light per day $(0700-1900 \mathrm{~h})$. Observations were made during daylight hours only.

Breeding cages were inspected for births at .5 -h intervals throughout the day of expected parturition. When birthing was observed, the breeding cage was checked unobtrusively every 5 min until at least three pups were present. At this time, two pups were selected randomly and were inspected to make sure that no milk bands were present. These pups were sexed, weighed, and placed immediately in a temperature-controlled environment $\left(33-34^{\circ} \mathrm{C}\right)$ to maintain their body temperatures until testing occurred, 5 to $15 \mathrm{~min}$ later.

Lactating surrogate dams, maintained on standard lab chow prior to and following delivery, were used to test the pups' suckling response. Prior to testing, a test dam was injected $(0.6 \mathrm{ml} / \mathrm{kg}$ ip) with sodium pentobarbital $(45 \mathrm{mg} / \mathrm{kg})$. When the dam was thoroughly anesthetized, she was placed in a supine position in a Plexiglas cage with a floor temperature maintained at $33-34^{\circ} \mathrm{C}$. A biological pup of the test dam was then allowed to suckle on the left midnipple for $1 \mathrm{~min}$, since previous data had indicated that this facilitates subsequent pup attachment.

Each test neonate was then individually held against the dam so that the pup's mouth was in contact with the nipple. The body of the pup was supported by the experimenter, and the pup was held in this position until nipple attachment was com- 
plete or until $5 \mathrm{~min}$ had elapsed. Attachment to the test dam was easily recognized, as the pup stopped all body movement.

\section{RESULTS}

The computation of maternal data was based on 38 mothers in the 35\% EDC group, 34 mothers in the $0 \%$ EDC group, and 32 mothers in the LC group. The $35 \%$ EDC mothers consumed an average of $13.7 \mathrm{~g}$ of ethanol per kilogram of body weight per day. An analysis of variance yielded a significant effect of prenatal history for percentage of maternal weight gain during pregnancy $[\mathrm{F}(2,101)=28.22, \mathrm{p}<.001]$. A NewmanKeuls test indicated that the 35\% EDC group did not differ from the 0\% EDC group (37\% vs. $35 \%$ weight gain), but that the LC group differed from both of these groups $(47 \%$ gain) $(\mathrm{p}<.01)$. An analysis of variance on gestational length also showed a significant effect of prenatal history $[F(2,101)=13.77, p<.001]$. NewmanKeuls showed that the 35\% EDC group had a longer gestation period than both the 0\% EDC and the LC groups $(\mathrm{p}<.05)$, which did not differ from each other. Litter size was not affected by prenatal treatment.

The mean litter weight of pups used in this study was also affected by prenatal history $[\mathrm{F}(2,75)=17.77$, $\mathrm{p}<.001]$. A Newman-Keuls analysis indicated, however, the only significant difference to be between the $\mathrm{LC}$ and the 35\% EDC groups ( $\mathrm{p}<.05)$.

Since attachment latencies among neonates were highly variable, the data were dichotomized in terms of the number of litters in which at least one of the two pups tested did not attach within the $300-\mathrm{sec}$ ceiling. A two-tailed chi-square test was performed on these data and was found to be significant $\left[\chi^{2}(2)=7.26\right.$, $\mathrm{p}<.05$ ]. Fifty-three percent (8 of 15) of the 35\% EDC litters had at least one pup that failed to attach prior to criterion, compared with $30 \%$ (3 of 10 ) of the $0 \%$ EDC litters and $7 \%$ (1 of 13$)$ of the LC litters.

\section{DISCUSSION}

This study attempted to alleviate postnatal effects that may have contributed to previous findings of an increase in nipple attachment latencies in animals exposed to alcohol prenatally (Chen et al., 1982). The data from the present study are in agreement with those previous results and indicate that, in general, pups selected from litters exposed to alcohol prenatally take longer than do controls to attach to the nipple of an anesthetized test dam. Since the pups tested in the present study did not have any suckling experience prior to the test, any preexperimental, postnatal experiences were unlikely to have influenced the results. Thus, the possibility that the results of earlier testing conducted at 3 days of age were due to the neonates' having some negative experiences associated with suckling was eliminated. Rather, the dysfunction in suckling behavior appears to have been a consequence of the prenatal exposure to alcohol. Furthermore, the present data complement the clinical observations of poorer suckling behavior in human neonates exposed to alcohol.

However, the present experiment still leaves open to question the reason for increased latencies in suckling. Prenatal alcohol exposure may produce a deficit in one or more sensory systems important for the establishment of normal suckling behavior. Olfaction has been shown to be an important cue for the establishment of suckling behavior in the rat (Rouger, Tobach, \& Schneirla, 1967; Singh, Tucker, \& Hofer, 1976), and it may be that animals exposed to alcohol prenatally show a temporary sensory deficit, making it more difficult for them to locate and attach to the nipple. Obviously, more work is needed before the underlying mechanism for this deficit can be isolated.

\section{REFERENCES}

Chen, J. S., Driscoll, C. D., \& Riley, E. P. (1982). Ontogeny of suckling behavior in rats prenatally exposed to alcohol. Teratology, 26, 145-153.

Chen, J. S., Riley, E. P., \& Driscoll, C. D. (April 1981). Ontogeny of suckling in rat pups prenatally exposed to ethanol. Paper presented at the National Council on Alcoholism Forum, New Orleans.

Jones, K. L., \& Sмith, D. W. (1973). Recognition of the fetal alcohol syndrome in early infancy. Lancet, 2, 999-1001.

Martin, D. C., Martin, J. C., Streissguth, A. C., \& Lund, C. A. (1979). Sucking frequency and amplitude in newborns as a function of maternal drinking and smoking. In M. Galanter (Ed.), Currents in alcoholism (Vol. 5). New York: Grune \& Stratton.

Oullette, E. M., Rosett, H. L., Rosman, N. P., \& Weiner, L. (1977). Adverse effects on offspring of maternal alcohol abuse during pregnancy. New England Journal of Medicine, 297, 528-530.

Plonsky, M., \& Riley, E. P. (1983). Head-dipping behaviors in rats exposed to alcohol prenatally as a function of age at testing. Neurobehavioral Toxicology and Teratology, 5, 309-314.

Rouger, Y., TовасH, E., \& Schneirla, T. C. (1967). Development of olfactory function in the rat pup. American Zoology, 7, $792-793$.

Singh, P. J., Tucker, A. M., \& Hofer, M. A. (1976). Effects of nasal $\mathrm{ZnSO}$ irrigation and olfactory bulbectomy on rat pups. Physiology \& Behavior, 17, 373-382.

UlleLAND, C. N. (1972). The offspring of alcoholic mothers. Annals of the New York Academy of Science, 197, 167-169.

Ulug, S., \& Riley, E. P. (1983). The effect of methylphenidate on overactivity in rats prenatally exposed to alcohol. Neurobehavioral Toxicology and Teratology, 5, 35-39.

(Manuscript received for publication December 27, 1983.) 